\title{
PERCEPÇÕES DE DISCENTES QUANTO A IMPORTÂNCIA E SATISFAÇÃO DE ITENS: ESTUDO DE CASO EM UM CURSO TÉCNICO DE FARMÁÇA
}

\section{Gabriella Lima Viana CHAGAS ${ }^{1,2}$, Eduardo SHIMODA ${ }^{2 *}$, Fabrício Ferreira de Albuquerque FERNANDES, Alessandra Lobo da Silva ROSA ${ }^{1,2,4}$, Nathália Ramos Ribeiro ROSA ${ }^{2}$, Erik da Silva OLIVEIRA ${ }^{2}$ \& Aldo SHIMOYA ${ }^{2}$}

1 Serviço Nacional de Aprendizagem Comercial. Campos dos Goytacazes, Rio de Janeiro, Brasil.

2 Universidade Candido Mendes. Campos dos Goytacazes, Rio de Janeiro, Brasil.

3 Instituto Federal de Educação, Ciência e Tecnologia Fluminense - Campus Guarus. Campos dos Goytacazes, Rio de Janeiro, Brasil.

4 Universidade Estácio de Sá - Campos dos Goytacazes, Rio de Janeiro, Brasil.

*Autor para correspondência: shimoda@ucam-campos.br

DOI: http://dx.doi.org/10.18571/acbm.123

\section{RESUMO}

O objetivo deste trabalho foi identificar os pontos críticos de um curso técnico em farmácia, visando a posterior adoção de estratégias para melhorar os cursos e reduzir o índice de evasão. Para tal, foi elaborado um questionário contendo 16 itens relacionados às condições socioeconômicas e familiares; à qualidade / infraestrutura escolar; aos aspectos gerais relativos ao curso; à qualidade do curso / ensino na instituição e ao relacionamento entre docente e aluno, sendo que os entrevistados atribuíam notas de 1 a 5 quanto à importância e à satisfação com estes itens. Foram entrevistados 91 alunos de um curso técnico em farmácia localizado em Campos dos Goytacazes, durante os meses de junho e julho de 2015. Para análise dos dados, foram utilizados os métodos de Satisfação simples, análise de GAP, Importância versus Satisfação, Abordagem Multiplicativa (Insatisfação Ponderada). Como resultado, verificou-se que são pontos a serem melhorados por terem alta importância e baixa satisfação: "Estágio"; "Atualização do curso quanto a novos produtos farmacêuticos"; "Estrutura física dos laboratórios"; "Oportunidade de emprego e mercado local favorável"; "Visitas técnicas"; e "Palestras e contato com profissionais". Interessante notar que estes pontos críticos estão relacionados às práticas que envolvem ações por parte da instituição, da equipe de gestão e docentes que atuam no curso. Os resultados apontam para situações que talvez possam ser melhoradas construindo-se práticas cotidianas que favoreçam e despertem o interesse não somente dos alunos, mas também dos docentes, tais como cursos de formação continuada, práticas didáticas e pedagógicas.

Palavras chave: Questionário; Ensino; Evasão; Avaliação Institucional; Técnico em farmácia.

\begin{abstract}
The objective of this work is to identify, through institutional evaluation, the critical points in the technical course in pharmacy, with the aim to adopt strategies to improve the courses and reduce dropout rates. The evaluation consisted of questionnaires to 91 students from the technical course in pharmacy. These questionnaires had sixteen general questions about the socioeconomic and family circumstances; quality / school infrastructure; General aspects of the course; quality of course / teaching in the institution; and relationship between teacher and student. Then, based on a survey of these data, it applied descriptive methods to quantify the points assessed as positive, negative, important and critical. These methods are as follows: simple satisfaction; Gap analysis; Importance vs. Satisfaction; Multiplicative approach (Dissatisfaction weighted). So check that all items evaluated
\end{abstract}




\section{Biomedica Brasiliensia}

ISSN: $2236-0867$

deserve some important highlight that they were counted as points that should be improved in the course, as they present assessment of the importance with high rate, but low satisfaction. These items were Stage; Travel update on new pharmaceutical products; physical structure of laboratories; employment opportunities and favorable local market; Technical visits; and lectures and contact with professionals. It is noteworthy that the items evaluated with high importance and low satisfaction, are therefore those who initially deserve more attention and need for action to improve. This is because they are related to practices involving actions by the institution, the management team and teachers who work in the course. The results indicate situations that may perhaps be improved by building up daily practices that promote and arouse the interest not only of students but also of teachers, such as continuing education courses, teaching practices and pedagogical.

Keywords: Questionnaire; Education; Evasion; Institutional evaluation; Technician in pharmacy.

\section{Introdução}

A farmácia é uma área que possui características específicas e um sistema organizacional próprio, não podendo ocorrer improvisações e atuações amadoras, como ainda acontece em farmácias brasileiras. Isto se dá devido a evolução das farmácias, que se tornaram estabelecimentos comerciais, e atualmente entregues a leigos (GRECO, 2009).

A diversidade física, cultural e socioeconômica apresentada no Brasil, faz com que o modelo de ensino técnico necessite ser moldável e adaptável, sendo assim, os novos currículos passaram a satisfazer o mercado de trabalho, adaptando-se a demanda dos setores produtivos considerando as características regionais do país (ESPANHA, 2002).

A exigência de especialistas que detenham o nível técnico, tem crescido consideravelmente nos últimos anos no Brasil, e como resultado, tem se observado crescimentos anuais de alunos matriculados em cursos técnicos (MEC, 2015). Conforme Cunha (2000), a educação técnico-científica é tida como estratégica pelo Banco Mundial, em países em desenvolvimento, como o Brasil.

Segundo Belloni (1999), a evasão escolar pode ser estabelecida como a paralisação no período de estudo e os resultados desta ação podem gerar relevantes danos sociais, econômicos e familiares, afetando assim quase todos os níveis relacionados à educação. A evasão é uma das problemáticas que atrapalha, de forma geral, tanto as instituições de ensino privadas quanto às públicas, desde o nível primário até os cursos de pós-graduação (RIOS; SHIMODA; GOMES, 2010). Campos, Costa e Santos (2007) tratam a evasão escolar como abandono ou desligamento do educando do estabelecimento de ensino e relatam que essa circunstância pode ser um processo individual, podendo se propagar para o coletivo.

A evasão na escola média geral ou em ensinos técnicos pode estar ligada ao maior ou menor grau de democratização ao ingresso dos indivíduos a esse nível de ensino (DORE; LÜSCHERII, 2011). Uma gama de elementos pode estar relacionada a evasão de discentes, tais como os debatidos por Bardagi (2007), dentre os quais podem ser indicados questões familiares, econômicas, vocacionais e sociais. Segundo Baggi e Lopes (2010), admitir essas desigualdades deve ser o primeiro passo de uma escola de qualidade, caso contrário, terão muitos discentes incluídos no sistema escolar, porém um diminuto número irá realmente adquirir o conhecimento que o sistema de ensino e aprendizagem exige.

Sendo assim, os discentes são usuários dos inúmeros serviços proporcionados por determinada instituição de ensino e demonstram uma ampla cooperação no desenvolvimento de instrução e aprendizagem. Deste modo, uma investigação de quais aspectos os alunos consideram mais relevantes no valor da qualidade total do curso ou da disciplina é de grande importância (BEM, 2004). A 


\section{ACTA

avaliação de valor do serviço é uma atribuição da particularidade do serviço específico e dos sacrifícios envolvidos na obtenção do mesmo, além das características dos alunos (MIGUEL; SALOMI, 2004).

A avaliação institucional apresenta-se como ferramenta pedagógica e de gestão determinada pela Lei de Diretrizes e Bases de 1996, no combate à evasão, logo é possível amenizar tal problemática (BAGGI; LOPES, 2009). Os autores Freitas e Rodrigues (2003) enumeram outros fatores vinculados à insatisfação com o curso, sendo a avaliação institucional um dispositivo de entendimento de sensações de alunos e apontamento de itens críticos.

O objetivo deste trabalho é identificar, por meio de avaliação institucional, os pontos críticos no curso técnico em farmácia, visando propor estratégias para melhorar os cursos e reduzir o índice de evasão.

\section{Material e Métodos}

\subsection{Elaboração do Questionário}

A presente pesquisa foi realizada no período de junho e julho de 2015, em uma Instituição de Ensino Técnico privada do município de Campos dos Goytacazes e consistiu das seguintes etapas: Nos meses de junho e julho de 2015 foi aplicado questionário a 91 alunos do curso técnico em farmácia. Esse questionário possuía dezesseis perguntas gerais sobre o estudante "condições socioeconômicas e familiares", dez na percepção discente com relação ao curso "qualidade / infraestrutura escolar", "aspectos gerais relativos ao curso", "qualidade do curso / ensino na instituição" e cinco ligadas ao docente "relacionamento entre docente e aluno". A partir das respostas destes questionários, foi realizada, nesse mesmo período, a revisão de literatura sobre os itens mais encontrados, dentro do tema proposto. No mês de agosto de 2015, os dados foram tabulados, utilizando o programa Microsoft Excel, e os mesmos foram analisados utilizando o programa computacional SAEG versão 9.1.

No questionário, foram usados critérios para mensurar o grau de satisfação e de importância de cada item citado, através da escala de cinco pontos de Likert (LIKERT, 1932), sendo apresentadas 5 alternativas em gradação ( 1 a 5) e mais uma opção de abstenção (N- não sei / não quero opinar). A escala de julgamento para a importância adotada foi: 1- nada importante; 2- pouco importante; 3importância média; 4- importante; 5- muito importante. A percepção sobre a satisfação seguiu a escala: 1- muito ruim; 2- ruim; 3- regular; 4- bom; 5- muito bom.

Além da satisfação e importância dos itens, também constava no questionário a pesquisa sobre a intenção de permanência no curso, que por sua vez foi verificada com uso dos seguintes critérios: 1- certamente vou abandonar; 2 - é mais provável que eu abandone; 3 - talvez conclua, talvez abandone; 4- é mais provável que eu conclua; 5- certamente concluirei. Nesta pesquisa também foram coletados dados do perfil dos alunos como "turma", "estado civil", "faixa etária", "renda familiar", "exercício de atividade remunerada" e "participação econômica familiar".

Os questionários foram aplicados em sala, durante o período de aula, sendo preenchidos diretamente pelos alunos, após explanação pela docente. 


\section{ACTA

\subsection{Métodos para Análise da Satisfação}

Os dados obtidos do questionário definitivo foram tabulados e submetidos aos métodos descritos a seguir para que possam quantificar os pontos avaliados como positivos, negativos, importantes e críticos.

\subsubsection{Satisfação Simples}

O método Satisfação Simples consiste em calcular a satisfação média obtida para cada um dos atributos, de acordo com as respostas dos entrevistados através de uma escala de diferencial semântico, na qual um extremo significa que está totalmente insatisfeito e o outro indica que está totalmente satisfeito (LISBÔA, 2011). Os atributos que, segundo os respondentes, obtiverem menor satisfação média são considerados para possíveis melhorias (MATSUKUMA; HERNANDEZ, 2007). Esse método não leva em conta a importância dos atributos para o cliente, e desta forma não fornece quaisquer dados que possam ajudar a Administração a priorizar as ações ou desempatar os critérios com os mesmos índices de satisfação (FONTENOT; HENKE; CARSON, 2005).

\subsubsection{Análise de GAP}

O método através da Análise de GAP consiste em calcular a diferença entre as médias da importância, indicadora da expectativa de desempenho do cliente em relação ao atributo, e da satisfação de cada um dos atributos (MATSUKUMA; HERNANDEZ, 2007; LISBÔA, 2011). A importância é obtida através de uma escala de diferencial semântico, na qual um extremo significa que o atributo é sem importância e o outro indica que é muito importante (MATSUKUMA; HERNANDEZ, 2007). Os atributos que, segundo os resultados da Análise de GAP, forem classificados nas primeiras posições possivelmente receberão melhorias de forma prioritária (LISBÔA, 2011).

\subsubsection{Importância versus Satisfação}

Esse método consiste em plotar as médias de importância no eixo das abscissas (eixo x) e de satisfação no eixo das ordenadas (eixo y) em um gráfico, como podem ser vistos na Figura 1, formando um gráfico de quatro quadrantes: excedente, manter, atenção e melhorar. O quadrante superior esquerdo indica a satisfação está acima da média, mas a importância está abaixo da média indicando que os itens nesta posição estão com excedente. Já o quadrante superior direito apresenta a satisfação acima da média e também a importância acima da média. Os atributos posicionados neste quadrante devem ser mantidos. No quadrante inferior esquerdo tanto a importância quanto à satisfação estão abaixo da média. Os itens localizados nessa posição merecem atenção, uma vez que eles podem se tornar importantes. E finalmente, o quadrante inferior direito demonstra que a importância está acima da média, porém a satisfação está abaixo da média. Os itens deste quadrante necessitam de melhorias, devendo ser priorizados (MATSUKUMA; HERNANDEZ, 2007; LISBÔA, 2011; MARTINS et al., 2012).

Essa metodologia usada tem como objetivo identificar quais os atributos se encontram no quadrante melhorar e através desta identificação sugerir propostas e ações de melhoria para reverter a situação. Se vários atributos estiverem localizados neste quadrante e a instituição não possuir recursos para melhorar todos eles, deve-se concentrar naqueles com o maior grau de importância e o nível de satisfação mais baixo (FONTENOT; HENKE; CARSON, 2005). 


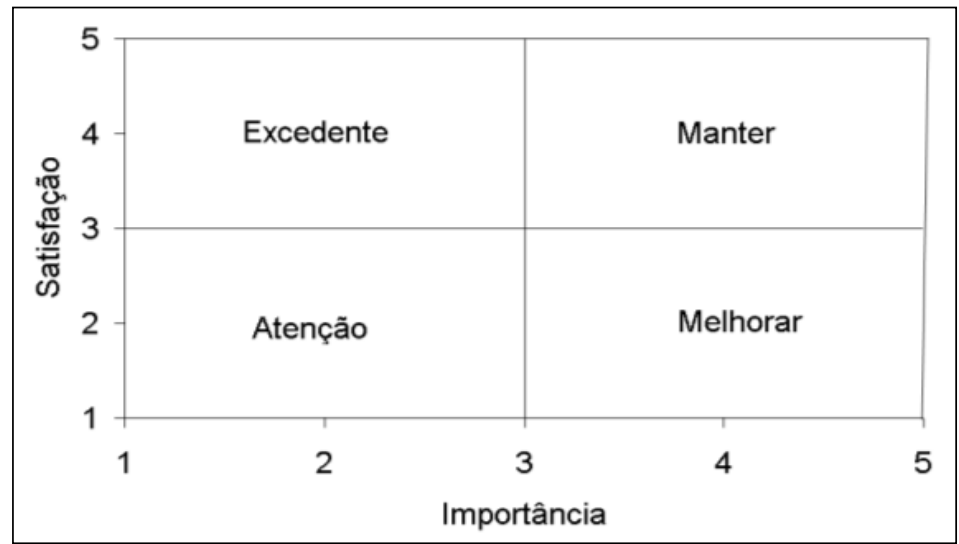

Figura 1: Modelo Importância versus Satisfação, Adaptado de Fontenot; Henke; Carson (2005).

\subsubsection{Abordagem Multiplicativa (Insatisfação Ponderada)}

A Abordagem Multiplicativa (Insatisfação Ponderada) é obtida através do cálculo da diferença entre a maior nota possível de satisfação, ou seja, quando o indivíduo está totalmente satisfeito, pela média de satisfação do atributo, sendo esse resultado multiplicado pela média da importância atribuída ao item pelos entrevistados. Os atributos que apresentarem os maiores valores são considerados críticos, devendo ter prioridade na implementação de melhorias (MATSUKUMA; HERNANDEZ, 2007; LISBÔA, 2011; MARTINS et al., 2012).

\section{Resultados}

\subsection{Importância e Satisfação}

A Figura 2 apresenta os graus de importância dos itens avaliados. Verifica-se que todos os itens apresentaram médias superiores a 3,5, sendo que os itens com maiores valores são aqueles considerados mais relevantes no ponto de vista dos estudantes. Em contrapartida, os itens com valores menores que 4,0 possuem importância menor. Desta forma, para os alunos do curso Técnico em Farmácia os itens de maior importância foram os seguintes: 29- Capacitação / conhecimento aparente $(4,89)$ foi identificado como o de maior importância pelos estudantes. Provavelmente este resultado foi devido ao fato de os mesmos preocupam-se com a qualidade do conhecimento que será transmitido para eles através dos docentes. Já o item 13- Dificuldade em conciliar o curso com o emprego $(3,56)$, não aparenta ser um item de grande relevância, o que poderia ser justificado pelo fato dos alunos terem como optar pelo turno do curso pretendido. 


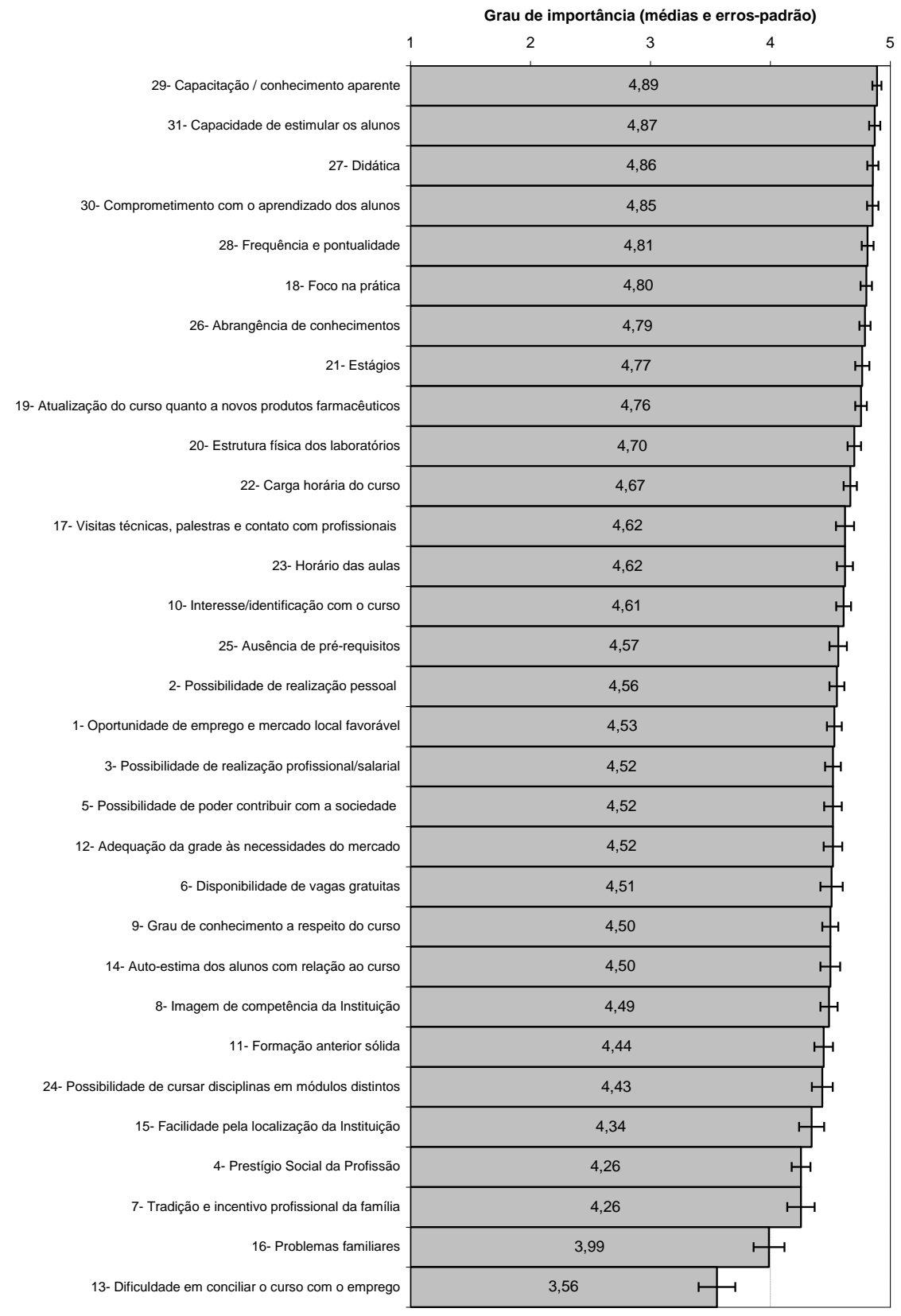

Figura 2: Grau de importância dos itens segundo a percepção dos discentes em ordem decrescente.

Pode-se observar que os itens "Oportunidade de emprego e mercado local favorável" e "Estágio" apresentaram médias inferiores a 3,0. Encontra-se na Figura 3 os itens avaliados em ordem decrescente de médias para melhor visualização dos resultados. 


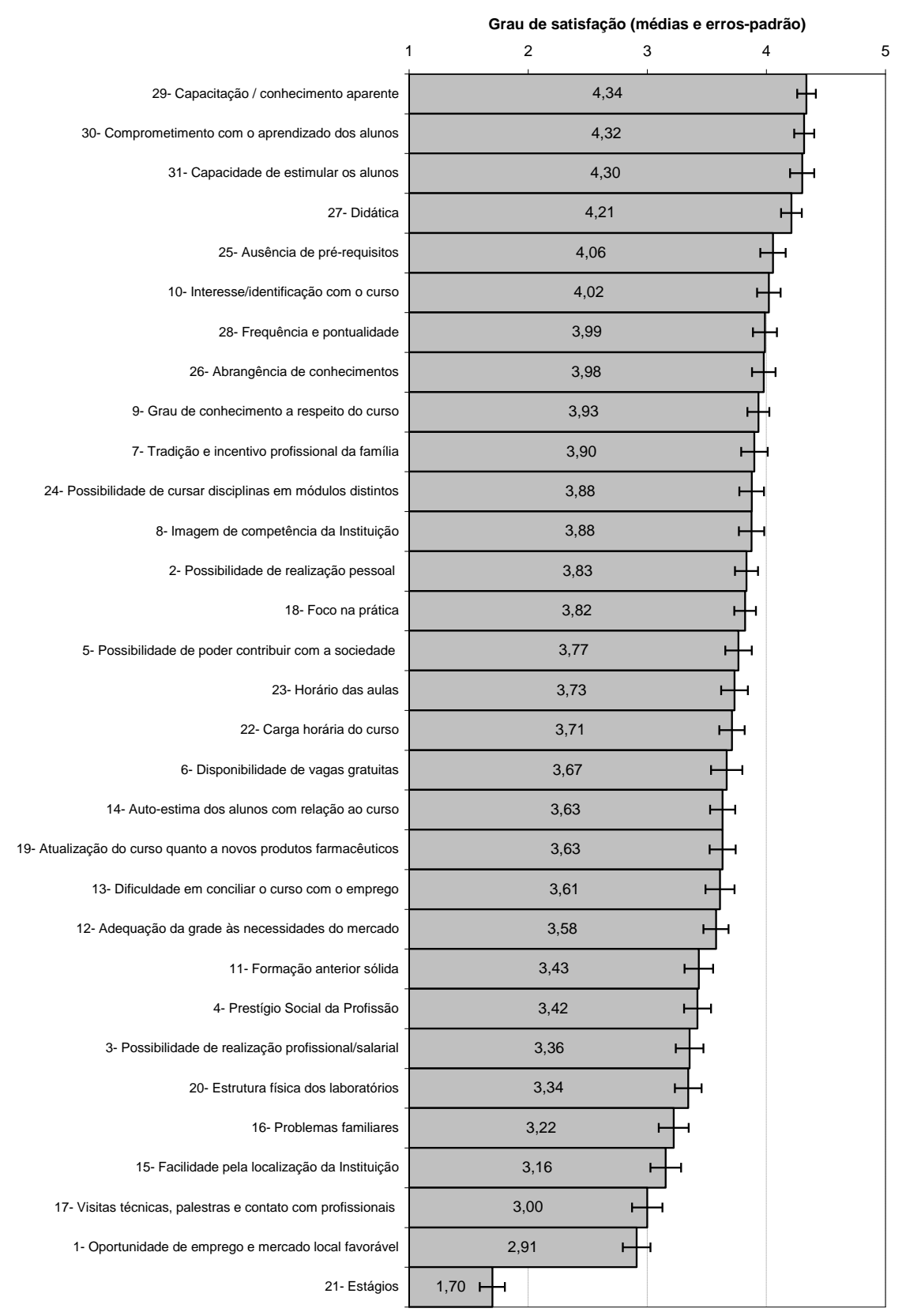

Figura 3: Grau de satisfação dos itens avaliados segundo percepção dos discentes.

Na Figura 3, que se referem ao grau de satisfação dos alunos, pode ser verificado que os itens: 29- Capacitação / conhecimento aparente $(4,34)$, 30- Comprometimento com o aprendizado dos alunos $(4,32), 31$ - Capacidade de estimular os alunos $(4,3)$, 27- Didática $(4,21)$, possuem as maiores médias de satisfação. Todos estes itens estão relacionados ao docente, demonstrando que provavelmente estes realizam um trabalho compatível com as expectativas dos discentes transmitindo o conhecimento de forma clara e objetiva. Já os itens: 21- Estágios (1,7) e 1- Oportunidade de emprego e mercado local favorável (2,91), demonstram baixa satisfação em relação aos discentes, provavelmente se deve ao fato da instituição não ter em sua grade curricular a disciplina "estágio" 


\section{ACTA \\ Biomedica Brasiliensia}

ISSN: 2236-0867

como obrigatória, sendo tal circunstancia na maioria das vezes um empecilho para que os discentes consigam vagas de estágio e posteriormente uma oportunidade de emprego.

\subsection{Método do GAP}

Na Figura 4 encontra-se as médias de importância e de satisfação e os valores do GAP para todos os itens avaliados segundo a percepção dos discentes. Pode-se observar que o item 21- Estágio foi o que apresentou o maior valor de GAP e o item 13- Dificuldade em conciliar o curso com o emprego foi o único que apresentou valor negativo. Para melhor visualização dos itens avaliados pelo método GAP, estes podem ser visualizados na Figura 4 que se encontram em ordem decrescente.

A Figura 4 apresenta a comparação entre a satisfação e a importância dos itens sob a ótica dos discentes em relação ao curso Técnico em Farmácia. É possível observar os itens cujos valores da diferença entre a importância e a satisfação são mais elevados, ou seja, valores de GAP maiores, e consequentemente merecem alta prioridade no esforço de buscas para melhoria.

Estes itens estão relacionados com os aspectos gerais do curso, tais como: 21 - Estágios $(3,07)$, 1- Oportunidade de emprego e mercado local favorável $(1,62), 17$-Visitas técnicas, palestras e contato com profissionais $(1,62), 20$ - Estrutura física dos laboratórios $(1,36), 15$ - Facilidade pela localização da Instituição (1,19), 3- Possibilidade de realização profissional/salarial (1,17), 19- Atualização do curso quanto a novos produtos farmacêuticos $(1,12), 11$ - Formação anterior sólida $(1,01)$.

Conforme demonstra a Figura 4, tais itens possuem grau de importância maior do que o grau de satisfação. O item 21- Estágios pode ser considerado crítico, uma vez que apresenta importância relativamente alta (média $=4,8$ - Figura 2) e a satisfação mais baixa (média = 1,7 - Figura 3), o que representa um GAP de 3,07 unidades.

No entanto o item: 13 - Dificuldade em conciliar o curso com o emprego $(-0,06)$ mostrou que os alunos estão satisfeitos, porém atribuem ao item baixa importância, e isso provavelmente está relacionado ao fato de que muitos alunos não trabalham ou optaram por turnos que não interferissem com sua atual ocupação. 


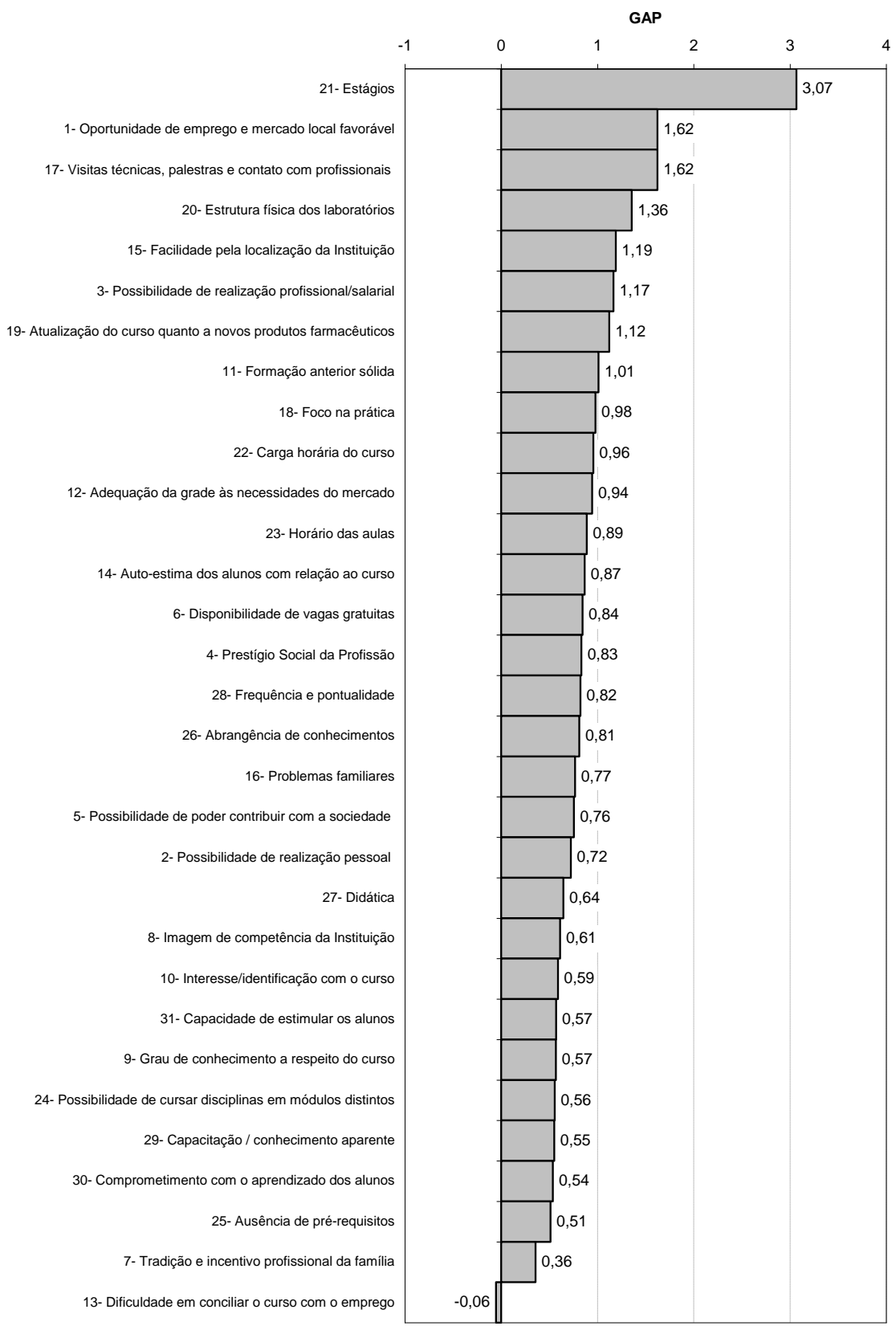

Figura 4: Valores do GAP referentes aos itens avaliados segundo a percepção dos discentes. 


\subsection{Método da Insatisfação Ponderada}

Na Figura 5, observam-se os cálculos para obtenção da Insatisfação Ponderada de cada item, segundo a percepção dos alunos do Curso Técnico de Farmácia.

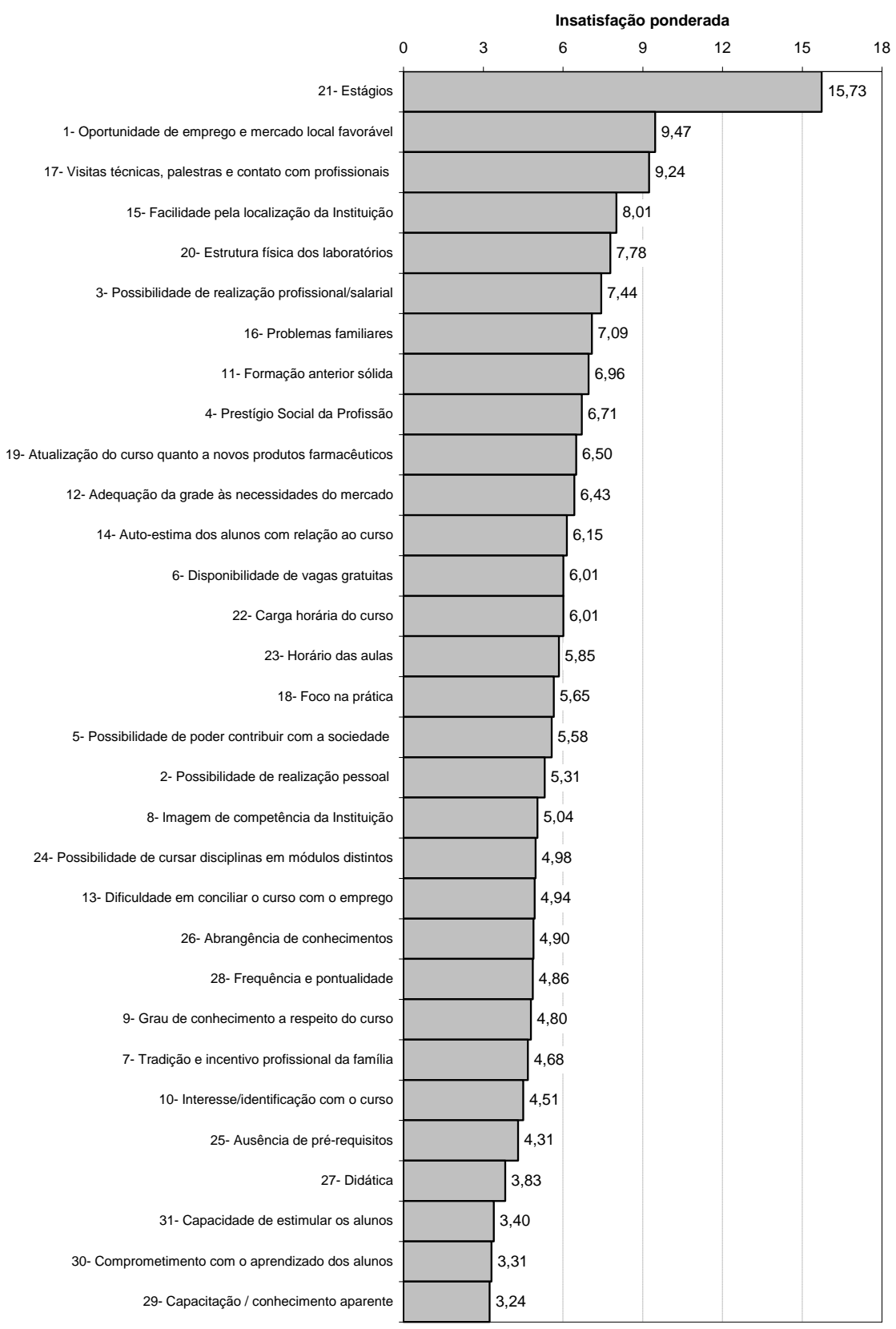

Figura 5: Insatisfação Ponderada dos itens avaliados segundo a percepção dos discentes.

Quanto à Figura 5 observa-se que os itens que estão diretamente relacionados aos aspectos gerais do curso são: 21- Estágios (15,73), 1- Oportunidade de emprego e mercado local favorável $(9,47)$, 17- Visitas técnicas, palestras e contato com profissionais $(9,24)$, 15- Facilidade pela localização da Instituição (8,01), 20- Estrutura física dos laboratórios (7,78), 3- Possibilidade de realização profissional/salarial $(7,44), 16$ - Problemas familiares $(7,09)$, detêm alta insatisfação e como 
consequência necessitam uma maior observação nos atos na investigação de possíveis melhorias. Grande parte dos discentes que ingressam no horário noturno trabalha durante o dia para estudar a noite, e traz com eles relevantes problemas sociais e familiares, o que pode interferir de maneira direta no desempenho escolar e processo de aprendizagem. Muitos apresentam fadiga e cansaço o que dificulta a continuidade no curso e por isso pode haver a evasão.

Em contrapartida os itens: 29- Capacitação / conhecimento aparente (3,24), 30Comprometimento com o aprendizado dos alunos (3,31), 31- Capacidade de estimular os alunos $(3,4)$, 27- Didática $(3,83)$ apresentam os itens escalonados de acordo com o sentimento de satisfação que os alunos expressam por determinado item. Vale ressaltar que tais itens estão ligados aos docentes, e com em favor dos resultados, estes devem ser mantidos.

\subsection{Método da Importância Versus Satisfação}

Na Figura 6 encontra-se o gráfico de dispersão contendo as médias de importância e de satisfação, segundo observância dos alunos da modalidade Técnica em Farmácia. Percebe-se que a maioria dos itens está plotado no quadrante manter, um item está no limite entre o quadrante manter e melhorar, e dois itens no quadrante melhorar. Os itens do quadrante "manter" apresentam tanto satisfação quanto importância acima da média e por isso não necessitam de atos de melhorias, devendo somente ser observados para manutenção dos mesmos. Entretanto, os itens que ficaram no quadrante "melhorar" possuem importância acima da média, porém satisfação abaixo da média. Esses itens devem ser observados como prioridade para realização de melhorias.

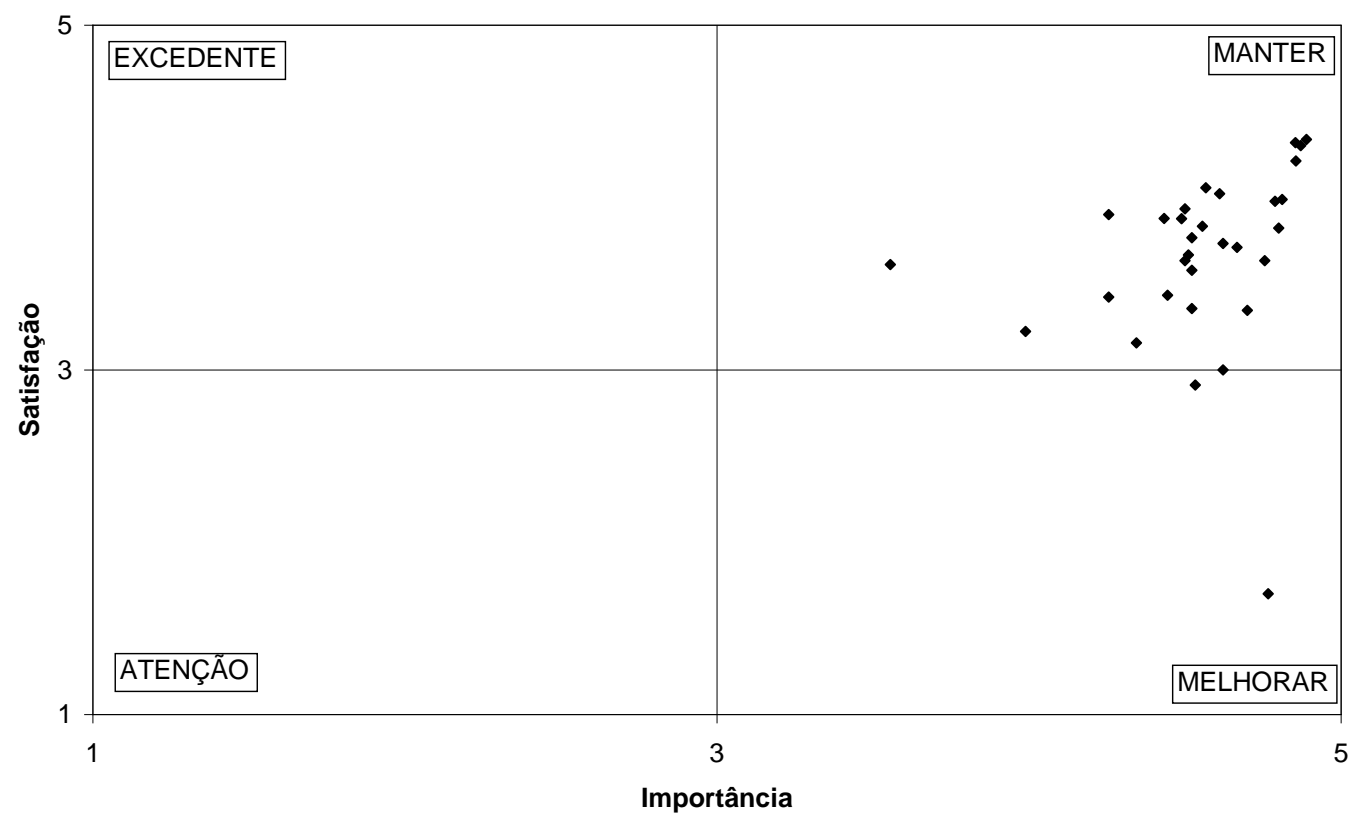

Figura 6: Dispersão das médias de importância e de satisfação dos itens avaliados pelos discentes.

Encontra-se na Figura 7 a ampliação dos quadrantes "manter" e "melhorar" contendo os itens avaliados no gráfico de dispersão da Figura 6, facilitando destacar o posicionamento e a classificação dos itens. 


\section{ACTA \\ Biomedica Brasiliensia}

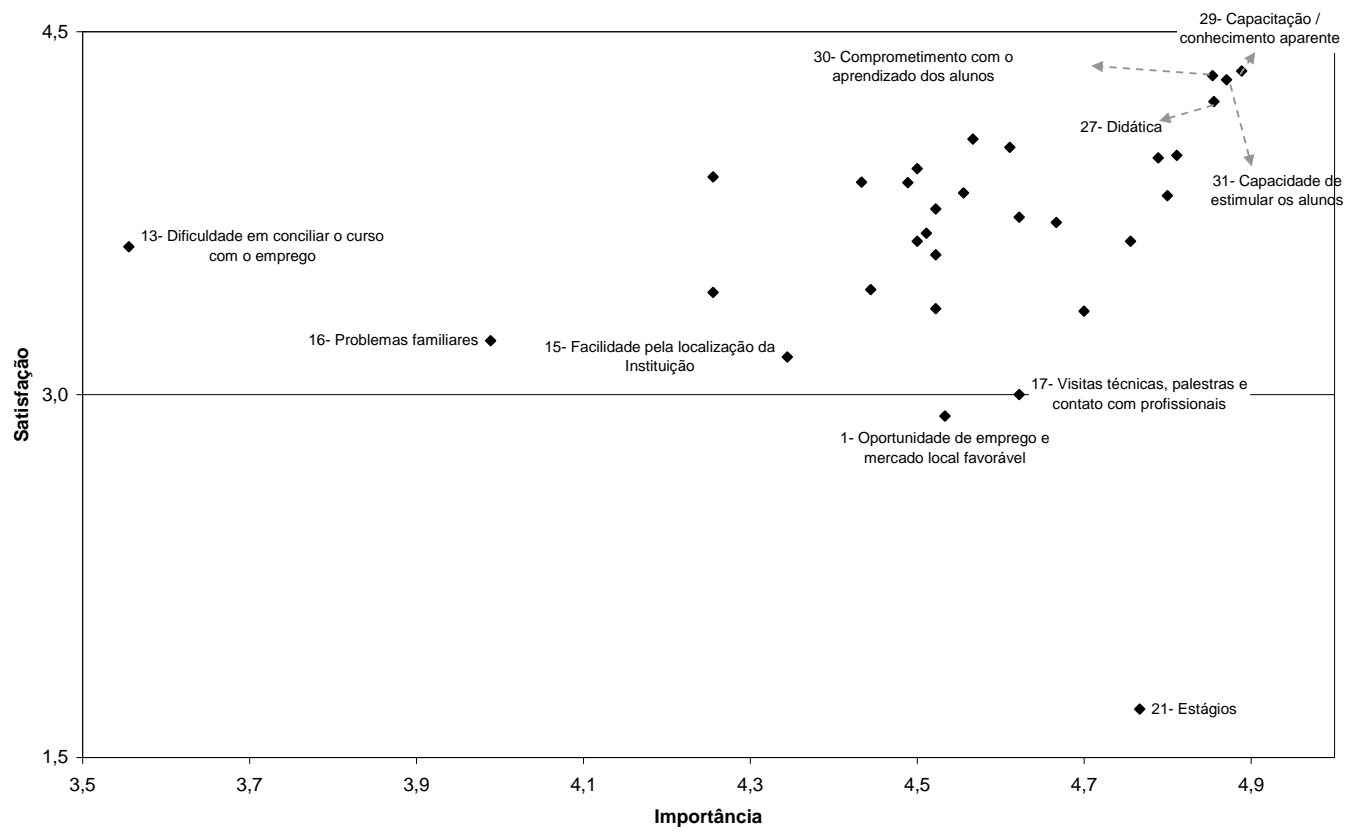

Figura 7: Ampliação da dispersão das médias de importância e de satisfação dos itens avaliados pelos discentes

Observa-se, na Figura 7, no quadrante manter, os itens 29- Capacitação / conhecimento aparente, 30- Comprometimento com o aprendizado dos alunos, 31- Capacidade de estimular os alunos, 27- Didática. Como já dito acima, tais itens apresentam satisfação e importância acima da média, portanto não precisam de ações de melhorias, necessitando somente da manutenção dos mesmos. Os dois itens que estão no quadrante "melhorar" precisam prioridade no esforço em busca de melhoria, estes itens são: 21- Estágios e 1- Oportunidade de emprego e mercado local favorável, pois apresentam satisfação abaixo da média e importância relativamente alta.

Há ainda o item 17- Visitas técnicas, palestras e contato com profissionais que está localizado no limite entre o quadrante manter e melhorar, que significa que este também deve receber certa atenção, propostas de melhorias e r monitorado, embora em caráter menos urgente.

\section{Discussão}

De todos os itens avaliados através da aplicação dos questionários aos discentes do curso técnico em farmácia de uma instituição de ensino particular, alguns merecem destaque importante por terem sido considerados como pontos que devem ser melhorados no curso, pois apresentam avaliação da importância com índice elevado, porém com baixa satisfação, estes itens são: 21- Estágios (1,2), 19- Atualização do curso quanto a novos produtos farmacêuticos $(0,56), 20$ - Estrutura física dos laboratórios $(0,47), 1$ - Oportunidade de emprego e mercado local favorável $(0,41)$, 17- Visitas técnicas, palestras e contato com profissionais $(0,41)$.

Vale ressaltar que os itens avaliados com alta importância e baixa satisfação, são, portanto, os que inicialmente merecem maior atenção e necessidade de ações para melhorar, uma vez que estão relacionados às práticas que envolvem ações por parte da instituição, da equipe de gestão e docentes que atuam no curso, uma vez que três dos seis itens que necessitam ser revistos e melhorados estão diretamente relacionados a instituição. 
Embora grande parte dos itens esteja no quadrante "manter", conforme Figura 8, dentro deste existe também um item que não é considerado crítico, porém merece atenção por estarem próximos ao quadrante "melhorar" e por se tratar de um item que envolve evasão por ser considerado problemáticas relacionada a instituição. Este item é: 17-Visitas técnicas, palestras e contato com profissionais que está localizado no limite entre o quadrante manter e melhorar, que significa que este também deve receber certa atenção, propostas de melhorias e ser monitorado, embora em caráter menos urgente.

Os itens: 21- Estágios (3,33), 1- Oportunidade de emprego e mercado local favorável $(2,22)$, 17- Visitas técnicas, palestras e contato com profissionais (2,22), 20- Estrutura física dos laboratórios $(1,89), 3$ - Possibilidade de realização profissional/salarial (1,56), 19- Atualização do curso quanto a novos produtos farmacêuticos $(1,56)$, são os que apresentam os maiores déficits de satisfação e os mesmos estão relacionados ao curso, ou seja, os alunos provavelmente estão insatisfeitos com os itens acima descritos, portanto os itens que devem ser tratados imediatamente.

Levando em consideração que pode haver na Instituição a possibilidade de realização de mais visitas técnicas e palestras na área do curso, deve-se inicialmente tentar sanar esta situação. Sendo este item sucedido do item 21, "Estágio", na avaliação como item insatisfatório, é interessante relevar que ambos parecem estar próximos de serem tratados, pois, sugere-se que, uma vez que seja possível haver incentivo e apoio Institucional, e o docente tome a iniciativa de realizar mais visitas técnicas, desta forma pode-se estar estimulando o aluno e tratando dois itens simultaneamente, evitando assim que ocorra evasão. Esta forma de estímulo não deve ser a única esperada pelos estudantes ou capaz de diminuir a insatisfação com os itens, porém possivelmente contribuirá. Os resultados apontam para situações que talvez possam ser melhoradas construindo-se práticas cotidianas que favoreçam e despertem o interesse não somente dos alunos, mas também dos docentes, tais como cursos de formação continuada, práticas didáticas e pedagógicas.

\section{Referências}

BAGGI, Cristiane Aparecida dos Santos. Evasão e Avaliação Institucional: uma discussão bibliográfica. 2010. 81 f. Dissertação (Mestrado) - Pontifícia Universidade Católica de Campinas, Campinas, 2010.

BAGGI, Cristiane Aparecida dos Santos; LOPES, Doraci Alves. Evasão e avaliação institucional no ensino superior: uma discussão bibliográfica. Avaliação, Sorocaba, SP, v. 16, n. 2, p.355-374, jul. 2011.

BAGGI, Cristiane Aparecida dos Santos; LOPES, Doraci Alves. Evasão no ensino superior: um desafio para a avaliação institucional? IX Colóquio Internacional sobre Gestão Universitária na América do Sul, Florianópols, p. 1-11, nov. 2009.

BARDAGI, Marúcia Patta. Evasão e comportamento vocacional de universitários: Estudos sobre o desenvolvimento de carreira na graduação. 2007. 230 f. Tese (Doutorado) - Curso de Psicologia, Universidade Federal do Rio Grande do Sul, Porto Alegre, 2007.

BELLONI, Maria Luiza. Educação à distância. Campinas, SP, 5 ed. Autores Associados, 1999. Disponível em: <https://books.google.com.br/books?hl=ptBR\&lr=\&id=BciuHdHIHPwC\&oi=fnd\&pg=PA3\&dq=Educa\%C3\%A7\%C3\%A3o+\%C3\%A0+dist \%C3\%A2ncia\&ots=ESK-QqhzyR\&sig=YsQVDcdwF6r5z- 
9HN3L5TapkzL0\#v=onepage \&q=Educa\%C3\%A7\%C3\%A3o\%20\%C3\%A0\%20dist\%C3\%A2ncia $\& \mathrm{f}=$ false $>$. Acesso em: 14 nov. 2014.

BEM, Amilton Barreto de. Confiabilidade e validade estatísticas da avaliação docente pelo discente: Proposta metodológica estudo de caso. 2004. 296 f. Tese (Doutorado) - Curso de Engenharia de Produção, Universidade Federal de Santa Catarina, Santa Catarina, 2004.

CAMPOS, Fernanda C. A.; COSTA, Rosa M. E.; SANTOS, Neide. Fundamentos da educação à distância, mídias e ambientes virtuais. Juiz de Fora: Editar Editora, 2007. Disponível em: $<$ http://pt.slideshare.net/marcelohenderson/fundamentos-da-educacao-a-distancia-midias-eambientes-virtuais>. Acesso em: 14 de nov. 2014.

CUNHA, Luiz Antônio. Ensino médio e ensino técnico na América Latina: Brasil, Argentina e Chile. Cad. Pesqui., [s.1.], v. 1, n. 111, p.47-69, dez. 2000.

DORE, Rosemary; LÜSCHERII, Ana Zuleima. Permanência e Evasão na Educação Técnica de nível médio em Minas Gerais. Cadernos de Pesquisa, São Paulo, v. 41, n. 144, p.770-789, dez. 2011.

ESPANHA. ORGANIZATION DE ESTADOS IBEROAMERICANOS. (Org.). Sistema educativo nacional de Brasil. 2002. Disponível em: 〈http://www.oei.es/quipu/brasil/educ_profesional.pdf>. Acesso em: 10 set. 2015.

FONTENOT, G.; HENKE, L.; CARSON, K. Take action on customer satisfaction. Quality Progress, v. 38 , n. 7 , p. $40-47,2005$.

FREITAS, A. L. P; RODRIGUES, S. G. A estrutura do processo de autoavaliação de IES: uma contribuição para a gestão educacional. In: Encontro Nacional de Engenharia de Produção, 23, 2003, Ouro Preto: Anais.... Ouro Preto: ENEGEP, 2003.

GRECO, Maria Cecília Machado. O Curso Técnico em Farmácia na ETSUS-SP: Contribuições Para o Debate. 2009. 123 f. Dissertação (Mestrado) - Curso de Mestrado Profissional em Gestão do Trabalho e da Educação na Saúde, Fundação Oswaldo Cruz, Rio de Janeiro, 2009.

Lei no 9.394, de 20 de dezembro de 1996. Estabelece as diretrizes e bases da educação nacional. Brasília, 20 de dezembro de 1996. Diário Oficial da República Federativa do Brasil. Brasília, 23 Dez. 1996.

LISBÔA, Rogério Trindade. Método do ranking ponderado de importância, satisfação e esforço para melhoria: descrição e comparação com outros métodos. 2011. 113 f. Dissertação (Mestrado) Universidade Candido Mendes, Campos dos Goytacazes, 2011.

MARTINS, Simara Netto et al. Método de Ranking Ponderado aplicado para identificar pontos críticos de uma casa lotérica. Revista FACEF Pesquisa: Desenvolvimento e Gestão, Franca, SP, v. 15, n. 3, p. 364-377, set/out/nov/dez. 2012.

MATSUKUMA, C.M.O; HERNANDEZ, J.M.C. Escalas e métodos de análise em pesquisa de satisfação de clientes. Revista de Negócios, Blumenau, v. 12, n. 2, p. 85 - 103, 2007. 
MIGUEL, Paulo Augusto Cauchick; SALOMI, Gilberto Eid. Uma revisão dos modelos para medição da qualidade em serviços. Produção, [s.l.], v. 14, n. 1, p.12-30, 2004.

RIOS, Erenildo da Silva; SHIMODA, Eduardo; GOMES, Geórgia Regina Rodrigues. Correlações entre índice de evasão e perfil acadêmico, financeiro e pessoal dos alunos: estudo de caso em uma universidade particular. In: ENCONTRO MINEIRO DE ENGENHARIA DE PRODUÇÃO, 6., 2010, Coronel Fabriciano. Anais... . Coronel Fabriciano: EMEPRO, 2010. v. 1, p. 1 - 9. 